\title{
A Educação no contexto da pandemia de COVID-19: uma revisão sistemática de literatura
}

\section{Title: Education in the context of the COVID-19 pandemic: a systematic literature review}

\author{
Márcia de Freitas Vieira \\ Laboratório de Educação a Distância e \\ eLearning(LE@D), Universidade Aberta \\ mfvieira@lead.uab.pt
}

\author{
Carlos Manuel Seco da Silva \\ Laboratório de Educação a Distância e \\ eLearning (LE@D), Universidade Aberta \\ cmsilva@lead.uab.pt
}

\begin{abstract}
Resumo
A pandemia de COVID-19 que acometeu a população mundial no início de 2020 exigiu dos governantes ações emergenciais nas mais variadas áreas da sociedade no intuito de conter a propagação da doença. As medidas de distanciamento social sugeridas pela Organização Mundial de Saúde (OMS) e adotadas na maioria dos países causaram o fechamento das escolas, o que impôs um novo modelo educacional, sustentado pelas tecnologias digitais e pautado nas metodologias da educação online. Este artigo busca refletir sobre o atual cenário educacional frente à pandemia causada pelo novo coronavírus, a partir de uma revisão sistemática de literatura das primeiras contribuições da comunidade cientifica brasileira e portuguesa sobre os efeitos e desafios da pandemia do COVID-19 na Educação. O estudo toma como base as produções publicadas no Portal de periódicos da CAPES, nos Repositórios Científicos de Acesso Aberto de Portugal-RCAAP, no SCIELO e no Google Scholar, no periodo de março/2020 a julho/2020 e revela desafios vivenciados por alunos e professores, estratégias adotadas pelos dirigentes escolares e professores para mitigar os efeitos da transição para o ensino e aprendizagem remotos e as perspectivas futuras para a educação.
\end{abstract}

Palavras-Chave: Educação; COVID-19; Ensino remoto de emergência; TIC; Competência digital.

\begin{abstract}
The COVID-19 pandemic that affected the world population in early 2020 required governments to take emergency actions in the most varied areas of society in order to contain the spread of the disease. The measures of social distance suggested by the World Health Organization (WHO) and adopted in most countries caused the closure of schools, which imposed a new educational model, supported by digital technologies and based on online education methodologies. This article seeks to reflect on the current educational scenario facing the pandemic caused by the new coronavirus, based on a systematic literature review of the first contributions of the Brazilian and Portuguese scientific community on the effects and challenges of the COVID-19 pandemic in Education. The study takes as a basis the productions published in the CAPES periodicals Portal, in the Scientific Open Access Repositories of Portugal - RCAAP, in SCIELO and in Google Scholar, in the period from March / 2020 to July / 2020 and reveals challenges experienced by students and teachers, strategies adopted by school leaders and teachers to mitigate the effects of the transition to remote teaching and learning and future prospects for education.
\end{abstract}

Keywords: Education; COVID-19; Emergency remote teaching; ICT; Digital competence.

Cite as: Vieira, M. F. \& Seco, C. (2020). Education in the context of the COVID-19 pandemic: a systematic literature review (A Educação no contexto da pandemia de COVID-19: uma revisão sistemática de literatura). Brazilian Journal of Computers in Education (Revista Brasileira de Informática na Educação - RBIE), 28, 10131031. DOI: 10.5753/RBIE.2020.28.0.1013 


\section{Introdução}

O ano de 2020 começa ameaçado pelo surto da COVID-19, uma doença causada pelo vírus SARS-CoV-2 ou novo Coronavirus. Em 30 de janeiro de 2020, a Organização Mundial de Saúde (OMS) declara emergência de saúde pública de importância internacional e no início de março de 2020 essa situação avança a uma pandemia, decorrente do surgimento de surtos da COVID-19 em vários países e regiões do mundo (OPAS/OMS-2020). Este cenário pandêmico exigiu das autoridades governamentais em todo o mundo a adoção de várias medidas, publicadas em instrumentos legais e normativos, no intuito de conter a propagação da doença. Políticas públicas emergenciais foram mundialmente criadas com objetivo de reduzir o impacto dessa pandemia.

As medidas de distanciamento social sugeridas pela OMS e adotadas na maioria dos países causaram o fechamento das escolas e suspensão das aulas presenciais da rede pública e privada em nível básico e superior (Almeida e Alves, 2020). Conforme os últimos dados divulgados pela Organização das Nações Unidas para a Educação, a Ciência e a Cultura (UNESCO), órgão que monitora os impactos da pandemia na educação, o fechamento das instituições de ensino afeta diretamente mais de $72 \%$ da população estudantil no mundo (UNESCO, 2020b).

No contexto educacional brasileiro, o Ministério da Educação decreta em 17 de Março de 2020, através da Portaria $n^{\circ} 343$, a suspensão de aulas presenciais e sua consequente substituição por atividades não presenciais ancoradas em meios digitais enquanto durar a situação de pandemia do novo Coronavírus (COVID-19). Também no contexto educacional português, em 12 de março de 2020, o Primeiro-Ministro anuncia o encerramento de todas as escolas do país a partir do dia 16 do mesmo mês, a fim de conter a propagação do surto de Covid-19; de modo que as aulas de todos os alunos do ensino básico e secundário mantiveram-se em regime online (Cabral, 2020).

Diante deste quadro, e num esforço de (re)organização do sistema educacional, a Organização para Cooperação e Desenvolvimento Econômico (OECD, 2020b) apresenta um conjunto de recomendações que é importante observar:

1) a necessária redefinição dos objetivos curriculares, definindo-se o que é realmente importante aprender/ensinar num período de distanciamento social;

2) a clarificação do papel do professor no suporte efetivo à aprendizagem dos alunos, combinando a instrução direta (à distância) e a orientação para uma aprendizagem auto-guiada;

3) a garantia do suporte e apoio necessários, aos estudantes e famílias mais vulneráveis, fomentando a sua participação ativa na implementação destes planos educativos alternativos;

4) a relevância de se implementar um sistema de comunicação, adaptado a cada estudante, no sentido de um acompanhamento, de perto, da sua aprendizagem.

A suspensão das atividades letivas presenciais por todo o mundo impôs aos gestores educacionais, professores e estudantes, o desafio de uma adaptação e transformação, até então, inimagináveis (OECD, 2020a), obrigando-os a um novo modelo educacional, sustentado pelas tecnologias digitais e pautado nas metodologias da educação online. Os professores se viram pressionados a migrarem para o ensino online, transferindo e transpondo metodologias e práticas pedagógicas típicas dos espaços de aprendizagem presenciais, naquilo que tem sido designado por ensino remoto de emergência (Moreira, Henriques e Barros, 2020).

$\mathrm{Na}$ contemporaneidade, e tempos antes da crise pandêmica provocada pelo SARS-CoV-2, a sociedade em rede (Castells, 1999) permeada pelo avanço dos recursos tecnológicos digitais e pelo desenvolvimento das telecomunicações, característicos da cibercultura (Lévy, 1997), tem demandado das instituições educacionais em todo o mundo o repensar dos processos de ensino e aprendizagem. Este paradigma educacional emergente implica a adoção de práticas pedagógicas 
que possibilite processos mais inovadores e dinâmicos nas relações entre professores e alunos, o que pressupõe a disrupção de princípios, crenças e atitudes próprias da escola tradicional (Vieira, 2018).

As tecnologias digitais emergentes propiciam uma maior flexibilidade espaço-temporal e mobilidade nos programas educacionais. No âmbito da educação à distância, uma pluralidade de cenários e estratégias inovadores flexibilizam pedagogicamente uma proposta educacional (Vieira, 2018), em busca de uma educação que rompa paradigmas e responda à demanda por conteúdo inovador para uma geração de alunos cada vez mais imersos na sociedade do conhecimento e da informação (Poy e Gonzales-Aguilar, 2014).

Contudo, as experiências de aprendizagem online bem planejadas são significativamente diferentes do ensino remoto que tem sido adotado pelas instituições educacionais em resposta à crise gerada pela COVID-19. Corroboramos com Hodges et al. (2020) e Joye et al (2020) de que o ensino remoto se diferencia fortemente da Educação a Distância $(\mathrm{EaD})$ pelo caráter emergencial que propõe a utilização das tecnologias em circunstâncias especificas onde até então praticava-se a educação presencial. Ensinar por meio de tecnologias digitais a estudantes afetados pelo fechamento repentino das escolas não é implementar educação a distância, ainda que se refira à mediação do ensino e da aprendizagem por meio das tecnologias digitais. De acordo com Hodges et al. (2020), o ensino remoto emergencial envolve o uso de soluções de ensino totalmente remotas para as aulas previamente elaboradas no formato presencial, constituindo-se em uma mudança temporária em resposta à situação da crise. Diferentemente da $\mathrm{EaD}$, é caracterizado pela disponibilização de videoaulas gravadas, aulas online e compartilhamento de materiais digitais em plataformas online (Arruda, 2020).

Esta mudança súbita nos processos educacionais tem gerado muitas incertezas por parte dos gestores das escolas, professores, estudantes, pais e comunidade científica acerca da efícácia do ensino não presencial, mediado pelas tecnologias digitais, quanto à aprendizagem, principalmente na educação básica e secundária, quando comparado ao ensino presencial a que todos estavam acostumados. O êxito na educação online depende de muitos fatores, que perpassam desde o perfil do aluno e a sua motivação para a aprendizagem, o acesso à conexão a internet e aos recursos tecnológicos, a formação e competência digital dos professores para a docência nesta modalidade de ensino. Ademais, a confusão conceitual que se tem feito entre a educação à distância e o ensino remoto de emergência que estamos vivenciando devido à pandemia. Na verdade, o surto de COVID-19 também é uma grande crise educacional (UNESCO, 2020a).

Neste contexto, a compreensão do impacto da COVID-19 sobre a Educação é de suma importância, no sentido de se buscar maneiras de aperfeiçoar as medidas ora tomadas para o futuro próximo. Este artigo apresenta os resultados de uma revisão sistemática de literatura das primeiras contribuições da comunidade científica brasileira e portuguesa sobre os efeitos e desafios da pandemia do COVID-19 na Educação, no intuito de identificar os impactos causados pela pandemia com o fechamento das escolas sobre a aprendizagem dos alunos e refletir sobre as potenciais intervenções de curto prazo que poderiam mitigar as consequências sofridas até então.

O texto está estruturado em quatro seções: na primeira apresentamos o contexto desse artigo, um estudo sobre a educação em tempos de pandemia devido ao COVID-19. Na segunda seção apresentaremos a metodologia, as questões e os protocolos de investigação; na terceira seção apresentaremos e discutiremos os resultados e por fim, na quarta seção traçaremos algumas considerações finais deste estudo. 


\section{Metodologia}

Para o alcance dos objetivos previamente definidos, foi adotada a estratégia de revisão sistemática da literatura de forma a identificar os estudos publicados sobre a temática. A Revisão Sistemática de Literatura (RSL) é uma forma de estudo secundário que utiliza um protocolo bem definido para identificar, analisar e interpretar toda a pesquisa disponível relevante para uma questão de pesquisa específica de uma maneira imparcial e (até certo ponto) repetível (Kitchenham e Charters, 2007), sendo uma metodologia de pesquisa com rigor científico e transparência, no sentido de produzir um retrato não enviesado do estado da arte, mediante uma recolha metódica dos textos publicados sobre a temática em questão (Faria, 2015). Para a estruturação deste artigo e relativo às etapas da revisão sistemática, tomamos como referência os autores Kitchenham e Charters (2007) e Faria (2015), no planejamento, condução e redação dos resultados.

\subsection{Delimitação das questões de investigação}

A partir do contexto apresentado muitos questionamentos sobre os desafios e delineamentos futuros dos métodos, ferramentas e sistemas adotados pelas escolas orientaram este estudo. Com o objetivo de identificar as primeiras contribuições das comunidades científicas brasileiras e portuguesas sobre os efeitos e desafios causados pela pandemia do COVID-19 na Educação, assim como as metodologias e estratégias adotadas pelas escolas de educação básica e secundária, foram definidas as seguintes questões de pesquisa:

Q1. Quais os impactos da COVID-19 na educação escolar brasileira e portuguesa? Qual a capacidade de resposta das instituições educacionais no processo de ensino frente à atual crise de COVID-19?

Q2. Quais dificuldades e desafios os professores e os alunos enfrentaram durante as aulas neste período de ensino remoto?

Q3. Quais tecnologias e plataforma (Moodle, Teams, Google Meet,etc) foram adotadas pelas escolas?

Q4. Quais metodologias e atividades (videoaulas, web conferências síncronas, atividades assíncronas) foram utilizadas pelos professores?

Q5. As estratégias adotadas garantiram a participação e aprendizagem de todos os alunos nas circunstâncias que vivemos?

Q6. Quais as tendências e os dilemas da Educação Básica e Secundária após a pandemia do COVID-19?

\subsection{Fonte de pesquisa}

As fontes de dados escolhidas inicialmente para a RSL englobam as publicações científicas do Portal de periódicos da CAPES, as bases de dados bibliográficos que compõem o Repositório Científico de Acesso Aberto de Portugal (RCAAP) e a Biblioteca Eletrônica Científica Online (SCIELO), por considerar estes, um espaço privilegiado de divulgação da produção científica dos centros de investigação das instituições de Ensino Superior do Brasil e Portugal. Como estas bases de dados retornaram poucos resultados (66), optamos por ampliar a busca com a utilização da ferramenta Google Scholar, de modo a obter mais estudos que pudessem contribuir para responder melhor as questões elencadas.

\subsection{Estratégias de busca}

A busca foi realizada em duas etapas. A primeira etapa envolveu a pré-seleção de estudos publicados no Portal de periódicos da CAPES, RCAAP e SCIELO, no ano de 2020, baseados em seus títulos e palavras-chaves, com a utilização da seguinte string de busca: (("COVID-19" OR "pandemia") AND ("Educação" OR "Ensino")). Esta busca identificou 74 publicações. A 
seguir, o processo de pesquisa foi replicado com a ferramenta de busca Google Scholar, com retorno de 129 publicações. Assim, o total de trabalhos resultantes da pesquisa foi de 203 publicações, conforme apresentado na Tabela 1. Em cada fonte de pesquisa foi utilizada a opção de busca avançada.

Tabela 1: Cadeias de busca e total de trabalhos resultantes.

\begin{tabular}{|c|c|c|c|c|c|}
\hline String & CAPES & RCAAP & SCIELO & $\begin{array}{l}\text { Google } \\
\text { Scholar }\end{array}$ & Total \\
\hline COVID-19 AND Educação & 6 & 12 & 13 & 45 & 76 \\
\hline COVID-19 AND Ensino & 8 & 7 & 4 & 17 & 36 \\
\hline Pandemia AND Educação & 4 & 5 & 2 & 42 & 53 \\
\hline Pandemia AND Ensino & 5 & 5 & 3 & 25 & 38 \\
\hline TOTAL & 23 & 29 & 22 & 129 & 203 \\
\hline
\end{tabular}

$\mathrm{Na}$ segunda etapa, todas as publicações resultantes da busca foram analisadas e a cada uma foram aplicados os critérios de inclusão e exclusão que são apresentados a seguir.

\subsection{Seleção dos estudos pelo resumo de acordo com os critérios de inclusão e exclusão}

Para a inclusão de um trabalho no estudo foi considerada sua relevância em relação às questões de investigação, determinada pela análise do título, palavras-chave e resumo. Especificamente, três critérios de inclusão foram definidos:

CI.1 - O trabalho relata experiências ou estudos empíricos de ensino durante o período de pandemia da COVID-19;

CI.2 - O trabalho apresenta reflexão teórica sobre metodologias e estratégias adotadas no período da pandemia para o ensino-aprendizagem, relacionado à organização, seleção de recursos, utilização e avaliação de atividades online;

CI.3 - O trabalho discute aspectos relativos às tecnologias utilizadas para o ensino remoto.

A seguir, foram excluídos os estudos que se enquadraram em algum dos seguintes critérios:

CE.1 - Estudos sem acesso disponível para visualização ou download do trabalho completo;

CE.2 - Estudos duplicados (derivados da mesma pesquisa ou resultantes em mais de uma fonte de busca);

CE.3 - Estudos cujo contexto de pesquisa não é a Educação Básica ou Secundária;

CE.4 - Publicações que não passaram por revisão por pares. Foram considerados para o estudo apenas artigo científico, capítulo de livro e contributo em revista;

CE.5 - Estudos com conteúdo irrelevante em relação aos domínios de pesquisa;

CE.6 - Estudos cujo país em questão não é Brasil ou Portugal.

Após a aplicação dos critérios de inclusão e exclusão, foram considerados 55 artigos pertinentes ao escopo deste estudo dentre os 203 artigos resultantes da busca. A Tabela 2 mostra o resultado geral da busca realizada e o número de artigos considerado em cada base de dados.

Tabela 2: Resultado primário da busca.

\begin{tabular}{|c|c|c|c|c|c|c|c|c|c|c|}
\hline Base de & Total de & \multirow{2}{*}{$\begin{array}{c}\text { Incluídos } \\
\text { Dados }\end{array}$} & publicações & & & \multicolumn{6}{|c|}{ Excluídos } & Total estudos \\
\cline { 4 - 11 } & & CE1 & CE2 & CE3 & CE4 & CE5 & CE6 & Total & pré-seleionados \\
\hline CAPES & 23 & 4 & 0 & 3 & 5 & 0 & 11 & 0 & 19 & 4 \\
\hline RCAAP & 29 & 6 & 0 & 3 & 8 & 2 & 10 & 0 & 23 & 6 \\
\hline SCIELO & 22 & 3 & 0 & 2 & 5 & 1 & 11 & 0 & 19 & 3 \\
\hline Google Scholar & 129 & 42 & 4 & 18 & 33 & 12 & 17 & 3 & 87 & 42 \\
\hline TOTAL & 203 & 55 & 4 & 26 & 51 & 15 & 49 & 3 & 148 & 55 \\
\hline
\end{tabular}

Destes, a grande maioria são estudos realizados no Brasil (50) e apenas cinco (5) em Portugal. 


\subsection{Seleção dos estudos primários}

Numa segunda fase do estudo, os 55 artigos incluídos na primeira fase pela análise dos resumos, foram lidos por inteiro e aplicados novamente os critérios de exclusão. Nesta fase foram rejeitados dois estudos, ambos da base de dados SCIELO: um por ser editorial e não ter sofrido revisão por pares e outro por ter o foco voltado para aspectos da área de psicologia. Dessa forma, foram selecionados 53 trabalhos relevantes para a extração de dados. Na Figura 1, ilustra-se essa fase da escolha dos estudos.

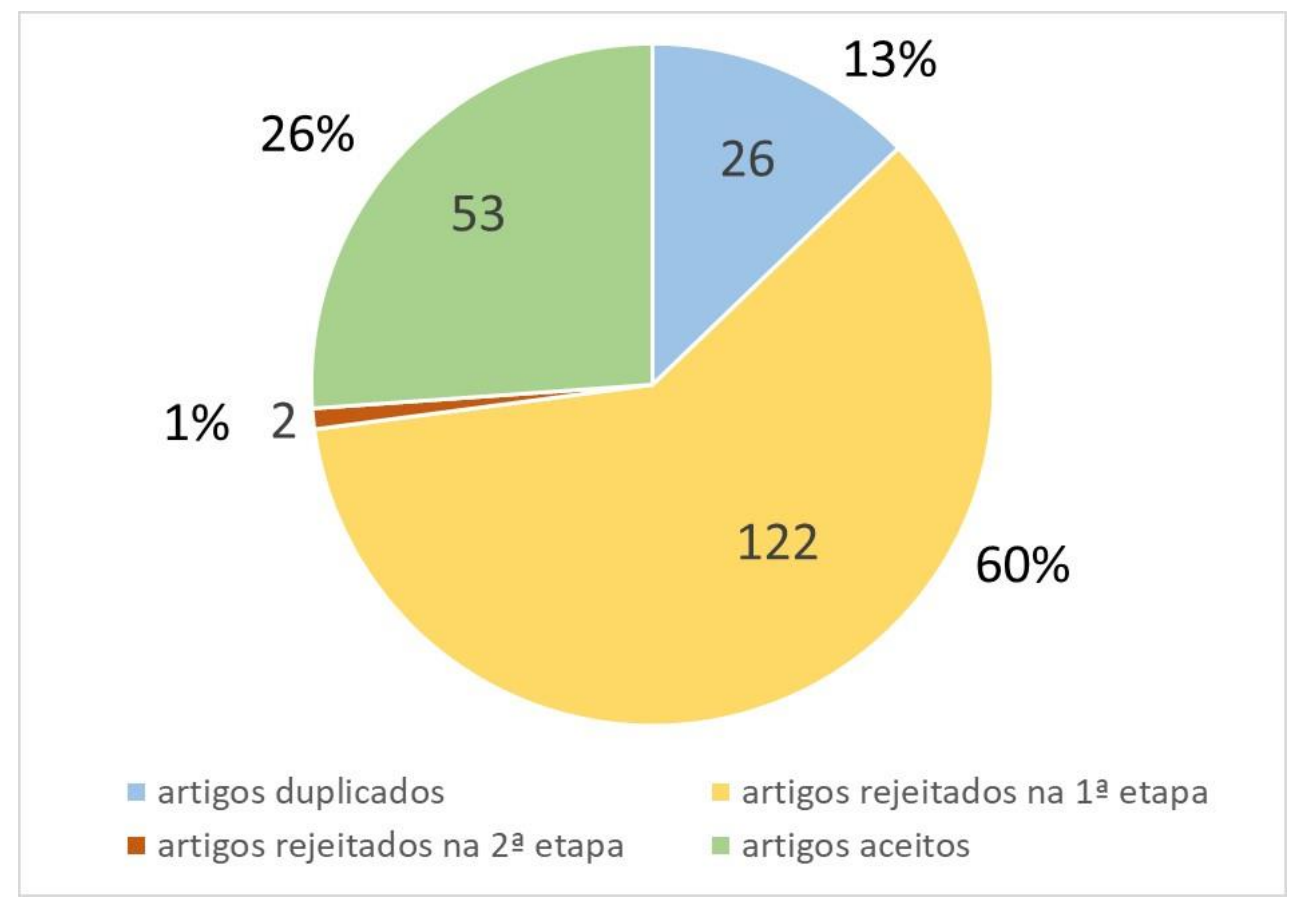

Figura 1: Resultados da fase de pré-seleção.

Fonte: Elaborado pelos autores

Dessa forma, para a constituição do corpus de análise do estudo, foram considerados 53 textos, tal como apresentado na tabela 3.

Tabela 3: Estudos resultantes da revisão de literatura.

\begin{tabular}{|c|c|c|c|c|c|c|}
\hline \multicolumn{2}{|c|}{ Fonte } & Revista & Título & Tipo & Metodologia & País \\
\hline & \multirow{4}{*}{ CAPES } & \multirow{4}{*}{$\begin{array}{l}\text { Research } \\
\text { Society and } \\
\text { Development }\end{array}$} & $\begin{array}{l}\text { Educação a Distância ou Atividade Educacional Remota Emergencial: em } \\
\text { busca do elo perdido da educação escolar em tempos de COVID-19 }\end{array}$ & Artigo & $\begin{array}{l}\text { Estudo de } \\
\text { Caso }\end{array}$ & BR \\
\hline & & & $\begin{array}{l}\text { Alunos em vulnerabilidade social em disciplinas de educação à distância } \\
\text { em tempos de COVID-19 }\end{array}$ & Artigo & $\begin{array}{c}\text { Revisão } \\
\text { Bibliográfica }\end{array}$ & BR \\
\hline & & & Práticas de ensino e alfabetização em tempos de pandemia do COVID-19 & Artigo & $\begin{array}{c}\text { Revisão } \\
\text { Bibliográfica } \\
\end{array}$ & BR \\
\hline & & & $\begin{array}{l}\text { Educação a distância no contexto da educação profissional e tecnológica: } \\
\text { considerações em tempos de pandemia }\end{array}$ & Artigo & $\begin{array}{c}\text { Revisão } \\
\text { Bibliográfica }\end{array}$ & BR \\
\hline \multirow{6}{*}{ 究 } & $\begin{array}{c}\text { Biblioteca } \\
\text { Digital IPB } \\
\end{array}$ & $\begin{array}{l}\text { Pedagogia em } \\
\text { Ação }\end{array}$ & $\begin{array}{l}\text { COVIDados a inovar e a reinventar o processo de ensino-aprendizagem } \\
\text { com TIC }\end{array}$ & Artigo & $\begin{array}{c}\text { Revisão } \\
\text { Bibliográfica } \\
\end{array}$ & $\mathrm{BR}$ \\
\hline & \multirow{3}{*}{$\begin{array}{l}\text { Universidade } \\
\text { Católica } \\
\text { Portuguesa }\end{array}$} & \multirow{3}{*}{ Veritati } & COVID e educação: da emergência às oportunidades & Capítulo & Narrativa & PT \\
\hline & & & Acesso, equidade e aprendizagem: desafios em tempos de Covid-19 & Capítulo & Narrativa & PT \\
\hline & & & $\begin{array}{l}\text { O ensino e a aprendizagem em tempos de COVID-19 à luz da teoria da } \\
\text { ação comunicativa de Habermas }\end{array}$ & Capítulo & $\begin{array}{c}\text { Pesquisa } \\
\text { Bibliográfica } \\
\end{array}$ & PT \\
\hline & $\begin{array}{l}\text { Universidade } \\
\text { Aberta }\end{array}$ & Dialogia & $\begin{array}{l}\text { Transitando de um ensino remoto emergencial para uma educação digital } \\
\text { em rede, em tempos de pandemia }\end{array}$ & Artigo & $\begin{array}{l}\text { Revisão } \\
\text { Bibliográfica }\end{array}$ & PT \\
\hline & $\begin{array}{l}\text { ESE Paula } \\
\text { Frassinetti }\end{array}$ & $\begin{array}{l}\text { Revista Galega } \\
\text { de Educacion }\end{array}$ & $\begin{array}{l}\text { Políticas educativas em tempos de COVID em Portugal: que relação com a } \\
\text { igualdade, equidade e inclusão em educação? }\end{array}$ & Artigo & $\begin{array}{c}\text { Análise } \\
\text { Documental }\end{array}$ & PT \\
\hline
\end{tabular}




\begin{tabular}{|c|c|c|c|c|c|}
\hline SCIELO & Ensaio & A Covid-19 e a volta às aulas: ouvindo as evidências & Artigo & $\begin{array}{c}\text { Revisão } \\
\text { Bibliográfica }\end{array}$ & $\mathrm{BR}$ \\
\hline \multirow{32}{*}{$\begin{array}{l}\text { GOOGLE } \\
\text { SCHOLAR }\end{array}$} & \multirow{3}{*}{ Em REDE } & $\begin{array}{l}\text { Educação remota emergencial: elementos para políticas públicas na } \\
\text { educação brasileira em tempos de Covid-19 }\end{array}$ & Ensaio & $\begin{array}{l}\text { Bibliográfica } \\
\text { e Documental }\end{array}$ & $\mathrm{BR}$ \\
\hline & & A COVID-19 e o fim da educação a distância: um ensaio & Ensaio & $\begin{array}{c}\text { Revisão } \\
\text { Bibliográfica }\end{array}$ & $\mathrm{BR}$ \\
\hline & & $\begin{array}{l}\text { A ressignificação da educação e o processo de ensino e aprendizagem no } \\
\text { contexto de pandemia da COVID-19 }\end{array}$ & Artigo & $\begin{array}{l}\text { Estudo de } \\
\text { caso }\end{array}$ & BR \\
\hline & RIEJS & A Covid-19 e o Direito à Educação & Artigo & Bibliográfica & $\mathrm{BR}$ \\
\hline & \multirow{2}{*}{\begin{tabular}{|} 
Brazilian \\
Journal health \\
Review
\end{tabular}} & $\begin{array}{l}\text { Educação à distância um marco civilizatório, um olhar holístico da } \\
\text { pedagogia: sinergia e reflexões na conectividade em tempos de COVID-19 }\end{array}$ & Artigo & $\begin{array}{l}\text { Bibliográfica } \\
\text { e Documental }\end{array}$ & $\mathrm{BR}$ \\
\hline & & $\begin{array}{l}\text { Metodologias e tecnologias para educação em tempos de pandemia } \\
\text { COVID-19 }\end{array}$ & Artigo & $\begin{array}{c}\text { Pesquisa } \\
\text { Bibliográfica } \\
\end{array}$ & $\mathrm{BR}$ \\
\hline & $\begin{array}{c}\text { Geografia } \\
\text { Médica e Saúde }\end{array}$ & COVID-19 e os impactos na educação: percepções sobre Brasil e Cuba & Ensaio & $\begin{array}{c}\text { Pesquisa } \\
\text { Bibliográfica } \\
\end{array}$ & $\mathrm{BR}$ \\
\hline & $\begin{array}{l}\text { Interfaces } \\
\text { científicas }\end{array}$ & \#Fiqueemcasa: educação na pandemia da COVID-19 & Ensaio & $\begin{array}{c}\text { Pesquisa } \\
\text { Bibliográfica }\end{array}$ & BR \\
\hline & \multirow{2}{*}{$\begin{array}{l}\text { Revista } \\
\text { Augustus }\end{array}$} & $\begin{array}{l}\text { Biopolítica e Educação: os impactos da pandemia de covid-19 nas escolas } \\
\text { públicas }\end{array}$ & Artigo & $\begin{array}{l}\text { Bibliográfica } \\
\text { e Documental }\end{array}$ & $\mathrm{BR}$ \\
\hline & & (Re)inventar educação escolar no Brasil em tempos da COVID-19 & Ensaio & Interrogativa & $\mathrm{BR}$ \\
\hline & \multirow{2}{*}{ Encantar } & COVID-19 e educação: resistências, desafios e (im)possibilidades & Ensaio & $\begin{array}{l}\text { Bibliográfica } \\
\text { e Documental }\end{array}$ & BR \\
\hline & & $\begin{array}{l}\text { Educação e COVID-19: as tecnologias digitais mediando a aprendizagem } \\
\text { em tempos de pandemia }\end{array}$ & Artigo & $\begin{array}{l}\text { Bibliográfica } \\
\text { e Documental }\end{array}$ & BR \\
\hline & \multirow{2}{*}{$\begin{array}{l}\text { Debates em } \\
\text { Educação }\end{array}$} & Educação e tecnologias em tempos de pandemia no Brasil & Artigo & $\begin{array}{l}\text { Bibliográfica } \\
\text { e Documental }\end{array}$ & BR \\
\hline & & $\begin{array}{l}\text { Letramento digital em tempos de COVID-19: uma análise da educação no } \\
\text { contexto atual }\end{array}$ & Artigo & Entrevista & BR \\
\hline & \multirow[b]{2}{*}{ Tamoios } & Educação geográfica, docência e o contexto da pandemia COVID-19 & Ensaio & Narrativa & $\mathrm{BR}$ \\
\hline & & $\begin{array}{l}\text { Alguns apontamentos para uma crítica da educação a distância (EaD) na } \\
\text { educação brasileira em tempos de pandemia }\end{array}$ & Artigo & Bibliográfica & $\mathrm{BR}$ \\
\hline & $\begin{array}{l}\text { Revista IFES } \\
\text { Ciência }\end{array}$ & $\begin{array}{l}\text { Educação e COVID-19: a arte de reinventar a escola mediando a } \\
\text { aprendizagem "prioritariamente" pelas TDIC }\end{array}$ & Artigo & Exploratória & $\mathrm{BR}$ \\
\hline & FGV & $\begin{array}{l}\text { Implicações da pandemia de COVID-19 para o financiamento das escolas } \\
\text { públicas de educação básica }\end{array}$ & Ensaio & $\begin{array}{l}\text { Bibliográfica } \\
\text { e Documental }\end{array}$ & $\mathrm{BR}$ \\
\hline & Série Educar & $\begin{array}{l}\text { O Papel dos licenciados em computação no apoio ao ensino remoto em } \\
\text { tempos de isolamento social devido à pandemia da COVID-19 }\end{array}$ & Ensaio & Questionário & $\mathrm{BR}$ \\
\hline & $\begin{array}{l}\text { Corpo } \\
\text { consciência }\end{array}$ & $\begin{array}{l}\text { A adesão dos alunos às atividades remotas durante a pandemia: realidades } \\
\text { da educação física escolar }\end{array}$ & Artigo & Questionário & $\mathrm{BR}$ \\
\hline & \multirow{3}{*}{$\begin{array}{l}\text { Boletim de } \\
\text { Conjunturas }\end{array}$} & $\begin{array}{l}\text { A prática de ensino de arte e educação física no contexto da pandemia da } \\
\text { COVID-19 }\end{array}$ & Artigo & $\begin{array}{c}\text { Descritivo } \\
\text { exploratório }\end{array}$ & $\mathrm{BR}$ \\
\hline & & $\begin{array}{l}\text { Museu, educação e o COVID-19: uma abordagem teórica dos acervos } \\
\text { digitais em meio ao isolamento social }\end{array}$ & Ensaio & $\begin{array}{l}\text { Bibliográfico } \\
\text { e Documental }\end{array}$ & $\mathrm{BR}$ \\
\hline & & A realidade da educação brasileira a partir da covid-19 & Ensaio & Bibliográfico & $\mathrm{BR}$ \\
\hline & $\begin{array}{c}\text { Ensino de } \\
\text { Biologia da } \\
\text { SBEnBio } \\
\end{array}$ & $\begin{array}{l}\text { Percepções docentes e práticas de ensino de ciências e biologia na } \\
\text { pandemia: uma investigação da Regional } 2 \text { da SBEnBio }\end{array}$ & Artigo & $\begin{array}{l}\text { Questionário } \\
\text { online }\end{array}$ & $\mathrm{BR}$ \\
\hline & \multirow{2}{*}{$\begin{array}{c}\text { Brazilian } \\
\text { Journal of } \\
\text { Development }\end{array}$} & $\begin{array}{l}\text { Princípio da sala de aula invertida: uma ferramenta para o ensino de } \\
\text { química em tempos de pandemia }\end{array}$ & Artigo & $\begin{array}{l}\text { Relato de } \\
\text { experiência }\end{array}$ & $\mathrm{BR}$ \\
\hline & & $\begin{array}{l}\text { Uso do Jogo Plague Inc.: uma possibilidade para o Ensino de Ciências em } \\
\text { tempos da COVID-19 }\end{array}$ & Ensaio & $\begin{array}{l}\text { Relato } \\
\text { experiência }\end{array}$ & $\mathrm{BR}$ \\
\hline & Revisa & $\begin{array}{l}\text { Ensino na pandemia: decisões do Instituto Federal de Roraima para o } \\
\text { Curso Técnico em Enfermagem }\end{array}$ & Artigo & $\begin{array}{l}\text { Análise de } \\
\text { conteúdo }\end{array}$ & $\mathrm{BR}$ \\
\hline & $\begin{array}{l}\text { Gestão \& } \\
\text { Tecnologia }\end{array}$ & Educação escolar no contexto de pandemia: algumas reflexões & Ensaio & Narrativa & $\mathrm{BR}$ \\
\hline & $\begin{array}{c}\text { Research, } \\
\text { Society and } \\
\text { Development } \\
\end{array}$ & $\begin{array}{l}\text { Em tempos de Coronavírus: reflexões sobre a pandemia e possibilidades de } \\
\text { abordagem no Ensino de Ciências a partir da Educação CTS }\end{array}$ & Ensaio & $\begin{array}{l}\text { Pesquisa } \\
\text { Bibliográfica }\end{array}$ & $\mathrm{BR}$ \\
\hline & $\begin{array}{c}\text { Revista } \\
\text { Prospectus }\end{array}$ & $\begin{array}{l}\text { Sobre ensino, aprendizagem e a sociedade da tecnologia: por que se refletir } \\
\text { em tempo de pandemia? }\end{array}$ & Ensaio & Narrativa & $\mathrm{BR}$ \\
\hline & $\begin{array}{c}\text { Ciência } \\
\text { Contemporânea }\end{array}$ & $\begin{array}{l}\text { Processo ensino aprendizagem na educação infantil em tempos de } \\
\text { pandemia e isolamento }\end{array}$ & Artigo & $\begin{array}{c}\text { Pesquisa } \\
\text { Bibliográfica }\end{array}$ & BR \\
\hline & Pedagogia em & Educação escolar e pandemia & Ensaio & Narrativa & $\mathrm{BR}$ \\
\hline
\end{tabular}




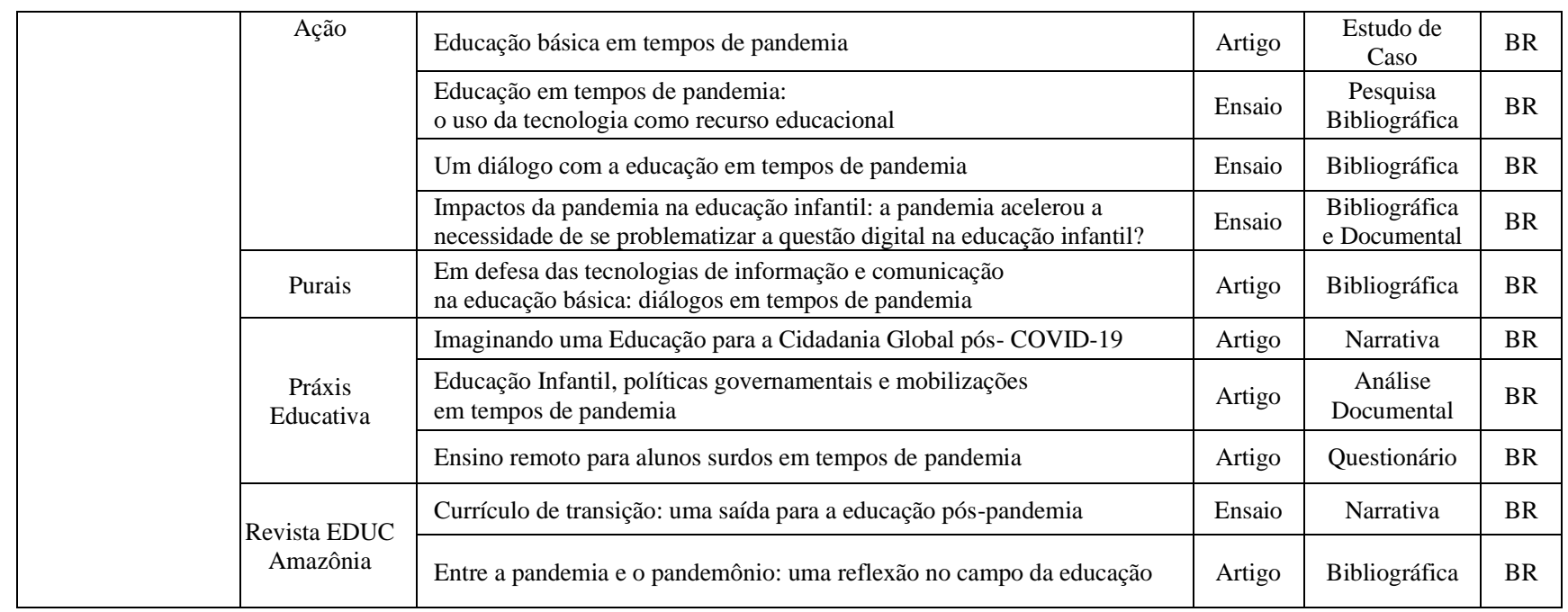

\subsection{Extração dos dados dos estudos selecionados}

Para uma melhor organização e avaliação dos estudos foi utilizada uma planilha (Petticrew \& Roberts, 2006) para a inserção dos dados gerais dos estudos incluídos, tais como: título do estudo, autores, assuntos, referencial teórico, objetivos, questões de pesquisa, localização temporal, contexto, instrumentos, participantes, principais conclusões, país, tipo de documento. Os estudos foram categorizados em quatro tipos (Tabela 4) de modo a permitir uma análise diferenciada de acordo com o objetivo do estudo e responder às problemáticas de pesquisa: Impactos da pandemia de COVID-19 na educação; utilização das tecnologias digitais; metodologias e práticas pedagógicas adotadas; análises prospectivas e oportunidades póspandemia.

Tabela 4: Categorização dos estudos.

\begin{tabular}{|c|c|c|}
\hline Categoria & Descrição & Questões \\
\hline 1 & Impactos da pandemia de COVID-19 na educação & Q1, Q2 \\
\hline 2 & Utilização das tecnologias digitais & Q3 \\
\hline 3 & Metodologias e práticas pedagógicas / inclusão & Q4, Q5 \\
\hline 4 & Análises prospectivas e oportunidades & Q6 \\
\hline
\end{tabular}

\section{Apresentação e discussão dos resultados}

Esta seção apresenta os resultados encontrados no estudo e as respostas às questões de pesquisa definidas no protocolo desta revisão sistemática da literatura. A nuvem de palavras representada pela figura 2 traz a imagem das palavras que mais apareceram entre as palavras-chave nos trabalhos selecionados. 


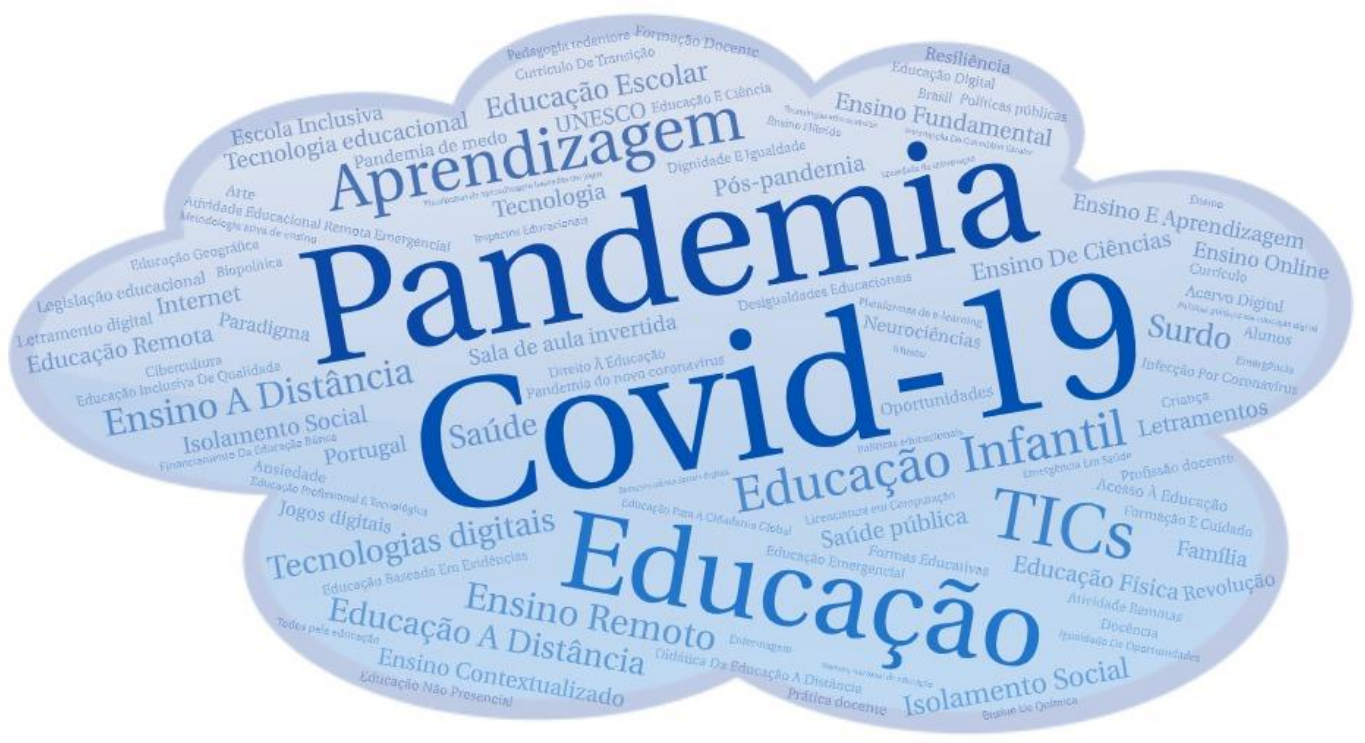

Figura 2: Nuvem de palavras produzida a partir das palavras-chave.

Fonte: Elaborado pelos autores

\subsection{Impactos da pandemia de COVID-19 na educação escolar no Brasil e em Portugal}

Nesta categoria, procuramos respostas às duas primeiras questões da investigação, que consistiam em mapear os impactos da pandemia de COVID-19 na Educação Básica e Secundária no Brasil e em Portugal: Quais os impactos da COVID-19 na educação escolar? Quais dificuldades e desafios os professores e os alunos enfrentaram durante as aulas neste período de ensino remoto?

A maioria dos trabalhos selecionados aborda os impactos e os desafios impostos aos professores e estudantes pela suspensão das aulas presenciais. Segundo os autores, é notório que o cenário pandêmico exigiu uma rápida adaptação das instituições de ensino para a educação remota, uma alternativa para dar continuidade ao ano letivo.

O maior desafio da educação brasileira passou a ser a adequação ao novo cenário imposto pela pandemia, em razão das medidas emergenciais adotadas pelos governantes e dirigentes escolares, nomeadamente, a adoção do ensino remoto nas escolas com utilização de plataformas digitais e sistemas gerenciadores de cursos remotos como alternativa à suspensão das atividades presenciais (Jesus Pereira, Narduchi e Miranda, 2020). Aliado a este, outro grande desafio é o desenvolvimento de habilidades e competências digitais docente, de maneira ainda mais urgente (Almeida e Alves, 2020). A implantação do ensino remoto vem evidenciando ainda mais as disparidades socioeconômicas e culturais existentes no Brasil (Almeida e Alves, 2020).

Na tabela abaixo, enumeramos os impactos na educação básica e secundária e os desafios aos dirigentes escolares, professores e alunos, identificados na literatura revista.

Tabela 5: Impactos e desafios impostos pela pandemia na educação.

\begin{tabular}{|l|l|}
\hline \multicolumn{1}{|c|}{ Autores } & \multicolumn{1}{c|}{ Impactos / Desafios } \\
\hline $\begin{array}{l}\text { Jesus Pereira; Narduchi } \\
\text { e Miranda (2020) }\end{array}$ & $\begin{array}{l}\text { Fechamento das escolas e suspensão das aulas presenciais. } \\
\text { Reorganização do calendário letivo por meio do ensino remoto. }\end{array}$ \\
\hline $\begin{array}{l}\text { Oliveira; Gomes e } \\
\text { Barcellos (2020) }\end{array}$ & $\begin{array}{l}\text { Limitações estruturais que dificultam a implementação de medidas efetivas. } \\
\text { Limitações associadas à qualidade do professor e ao acesso a tecnologias. } \\
\text { Consequências negativas para a aprendizagem dos alunos. }\end{array}$ \\
\hline Arruda (2020) & $\begin{array}{l}\text { Propostas difusas, que refletem a falta de liderança do Ministério da Educação. } \\
\text { Incipiência na apropriação de tecnologias digitais na educação pública. }\end{array}$ \\
\hline Silva Monteiro (2020) & Professores sem acesso a internet ou acesso limitado inviabiliza/dificulta o \\
\hline
\end{tabular}




\begin{tabular}{|c|c|}
\hline & $\begin{array}{l}\text { planejamento e implementação de ensino online. } \\
\text { Famílias sem condições financeiras para adquirir computador e internet em casa. } \\
\text { Aumento das desigualdades sociais. } \\
\text { Necessidade de (re)inventar a profissão docente em tempos de adversidade. }\end{array}$ \\
\hline $\begin{array}{l}\text { Almeida e Alves } \\
(2020)\end{array}$ & $\begin{array}{l}\text { Dificuldades de adaptação ao ensino remoto online. } \\
\text { Dificuldades de acesso às tecnologias digitais. } \\
\text { Ausência de um ambiente familiar que propicie o aprendizado remoto. } \\
\text { Ausência de letramento digital de professores e alunos. } \\
\text { Ausência de preparação pedagógica da maioria dos pais ou responsáveis para } \\
\text { acompanhar o desempenho educacional dos filhos. } \\
\text { Não adoção anterior pelos sistemas educativos de práticas educacionais com uso das } \\
\text { TIC como mediadoras do processo de ensino-aprendizagem. } \\
\text { Maior evidencia das disparidades socioeconômicas e culturais no país, assinaladas } \\
\text { pelas diferenças entre alunos das escolas públicas e alunos de escolas privadas. }\end{array}$ \\
\hline Cani et al. (2020) & $\begin{array}{l}\text { Falta de estrutura tecnológica das escolas. } \\
\text { Falta de formação dos professores e alunos para um uso crítico das tecnologias. }\end{array}$ \\
\hline $\begin{array}{l}\text { Coutinho e Côco } \\
(2020)\end{array}$ & $\begin{array}{l}\text { Impossibilidade de fazer escola sem corpos presentes. } \\
\text { Exige das professoras o domínio dos meios digitais, planejar e propor atividades } \\
\text { online, sem que tenham condições para isso. } \\
\text { Requer das famílias o trabalho pedagógico e recursos tecnológicos, ausentes em } \\
\text { grande parte dos lares brasileiros. }\end{array}$ \\
\hline Santos et al. (2020) & $\begin{array}{l}\text { Ausência de levantamento prévio acerca das condições de acesso a internet por } \\
\text { professores e alunos ( } 46 \text { milhões de brasileiros não possuem acesso a internet). } \\
\text { Grande parte das famílias não possui preparação para a ensino remoto em casa; } \\
\text { pouco suporte nas escolas públicas para que as TIC sejam utilizadas efetivamente. } \\
\text { Impacto negativo no processo ensino-aprendizagem. } \\
\text { Dificuldade de acesso às tecnologias, que induzem à exclusão. } \\
\text { Dificuldade dos professores na promoção do ensino remoto. } \\
\text { Falta de escolaridade dos pais e responsáveis para o acompanhamento dos alunos em } \\
\text { atividades a distância. }\end{array}$ \\
\hline $\begin{array}{l}\text { Couto, Couto e Cruz } \\
(2020)\end{array}$ & $\begin{array}{l}\text { Evidencia as desigualdades sociais e exclusão digital no Brasil (praticamente metade } \\
\text { da população não tem acesso à Internet ou tem acesso limitado e instável). }\end{array}$ \\
\hline Barreto e Rocha (2020) & $\begin{array}{l}\text { Dificuldade dos professores na promoção do ensino remoto - ausência de } \\
\text { competência digital. }\end{array}$ \\
\hline $\begin{array}{l}\text { Avelino e Mendes } \\
(2020)\end{array}$ & $\begin{array}{l}\text { Sistema de educação sem estrutura tecnológica suficiente para apoiar ensino remoto. } \\
\text { Crianças sem acesso a internet. } \\
\text { Ambiente em casa nem sempre propício a aprendizagem. } \\
\text { Ausência de formação inicial e continuada dos professores para utilização das TIC no } \\
\text { cotidiano escolar. }\end{array}$ \\
\hline Santana Filho (2020) & $\begin{array}{l}\text { Aumento da fragilidade na profissão docente. } \\
\text { Transferência de responsabilidade dos gestores para os professores quanto ao } \\
\text { cumprimento ou não dos dias letivos. } \\
\text { Decisões nebulosas do ponto de vista legal e administrativo, faltando o devido e } \\
\text { esclarecido respaldo na legislação vigente. } \\
\text { Sentimento de impotência e fragilidade nos docentes, e exposição ao assédio e } \\
\text { ameaças por não saberem transformar e produzir, com a devida urgência as } \\
\text { atividades online, no mesmo padrão das aulas presenciais. } \\
\text { Processo educacional focado no cumprimento de contéudos e na realização de } \\
\text { exercícios e atividades copiadas ou a sua reprodução pura e simples. } \\
\text { Tem gerado angústia nas famílias que precisam transformar suas salas em espaço de } \\
\text { aula e, ainda, ser os professores dos filhos. }\end{array}$ \\
\hline Moreira et al (2020) & $\begin{array}{l}\text { Muitos alunos tem ficado sem acesso ao estudo, principalmente os economicamente } \\
\text { desfavorecidos. }\end{array}$ \\
\hline $\begin{array}{l}\text { Nascimento Borba et } \\
\text { al.(2020) }\end{array}$ & $\begin{array}{l}\text { Demandas metodológicas sobre planejamento, avaliação e estratégias didáticas. } \\
\text { Aumento da carga de trabalho docente. } \\
\text { Dificuldades de acesso à internet por parte dos estudantes. }\end{array}$ \\
\hline Silveira et al. (2020) & $\begin{array}{l}\text { Ausência de interação entre escola, professores e família, de suma importância para } \\
\text { crianças até } 6 \text { anos. }\end{array}$ \\
\hline
\end{tabular}




\subsection{A utilização das tecnologias digitais no ensino remoto de emergência}

Nesta categoria, procuramos responder à terceira questão de pesquisa: Quais tecnologias e plataformas de aprendizagem foram adotadas pelas escolas?

Foi possível constatar, por meio de 30 (trinta) estudos elencados na revisão de literatura, que a maioria das instituições escolares e professores utilizaram plataformas digitais de aprendizagem, tecnologias de videoconferência, software para gravação de pequenos vídeos educativos e ferramentas para criação de recursos educativos online ou questionários para avaliação das aprendizagens (Avelino e Mendes, 2020; Cani et al., 2020; Gonçalves, 2020; Moreira, Henriques e Barros, 2020; Nascimento e Rosa, 2020; Santos Junior e Monteiro, 2020; Silveira et al., 2020). Segundo estes estudos, grande parte dos professores nunca tinham usado tais recursos, o que corrobora com a pesquisa realizada pelo Comitê Gestor da Internet no Brasil (CGI.BR, 2019) de que apenas $22 \%$ dos professores brasileiros já participaram de algum curso de formação continuada sobre o uso de computadores e internet nas atividades de ensino.

$\mathrm{Na}$ tabela 6, apresentamos algumas ferramentas tecnológicas utilizadas nas escolas, conforme apontadas pelos trabalhos em estudo.

Tabela 6: Recursos tecnológicos digitais que têm sido utilizados.

\begin{tabular}{|c|c|c|}
\hline Função/atividade & Ferramenta & Download \\
\hline \multirow{3}{*}{$\begin{array}{l}\text { Ambiente virtual de } \\
\text { aprendizagem }\end{array}$} & Moodle & https://moodle.org/ \\
\hline & Google Classroom & https://classroom.google.com \\
\hline & Microsoft Teams & https://teams.microsoft.com/ \\
\hline \multirow[t]{2}{*}{ Videoconferências } & Colibri Zoom & https://zoom.us/pt-pt/meetings.html \\
\hline & Google Meet & https://meet.google.com/ \\
\hline \multirow[b]{2}{*}{ Gravação de videoaulas } & LOOM & WWW.loom.com \\
\hline & Screencast-o-matic & screencast-o-matic.com \\
\hline Compartilhamento de vídeos & Youtube & https://www.youtube.com/ \\
\hline $\begin{array}{l}\text { Edição e compartilhamento de } \\
\text { arquivos }\end{array}$ & Google Drive & https://www.google.com.br/drive/apps.html \\
\hline Sala de aula invertida & - & - \\
\hline Criação de atividades lúdicas & Ardora & webardora.net \\
\hline \multirow{2}{*}{ Mural ou quadro virtual interativo } & Padlet & https://pt-br.padlet.com/ \\
\hline & Trello & https://trello.com/pt-BR \\
\hline \multirow{3}{*}{ Questionário online / Avaliação } & Quizizz & https://quizizz.com/ \\
\hline & Kahoot & https://create.kahoot.it/ \\
\hline & Quizlet & https://quizlet.com/pt-br \\
\hline Museu virtual e galerias de artes & Google Arts \& Culture & https://artsandculture.google.com \\
\hline Jogo de vídeo / simulação & jogo Plague Inc & https://play.google.com/ \\
\hline Podcast & Soundcloud & https://soundcloud.com/ \\
\hline Mapa mental & MindMeister & https://www.mindmeister.com/pt \\
\hline Livro virtual & Livros Digitais & https://www.livrosdigitais.org.br \\
\hline \multirow{2}{*}{ Laboratório virtual } & $\begin{array}{l}\text { Laboratório Virtual de } \\
\text { Química e Física }\end{array}$ & http://www.labvirt.fe.usp.br/ \\
\hline & $\begin{array}{c}\text { Virtual Labs Química, Física } \\
\text { e Biologia }\end{array}$ & http://virtuallab.pearson.com.br \\
\hline
\end{tabular}

Fonte: Avelino e Mendes (2020); Cani et al. (2020); Gonçalves (2020); Nascimento, Benedetti e Santos (2020); Santos Junior e Monteiro (2020); Silveira et al. (2020); Moreira; Henriques e Barros (2020).

Os sistemas gerenciadores de cursos online (Moodle, Sakai, Chamilo, Google Classroom, Microsoft Teams) têm sido um recurso fundamental para a mediação dos processos de aprendizagem. Aliado a estes, os sistemas de videoconferência (Colibri Zoom, Cisco Webex, Google Meet, Skype); os recursos para gravação de videoaulas ou capturar o ecrã em vídeo (LOOM, Screencast-o-matic) que permitem ao professor ilustrar a aula expositiva com apresentações eletrônicas; e recursos digitais para auxiliar a avaliação formativa (Google Forms, 
Microsoft Forms, nearpod, kahoot, Socrative, Quizlet, Quizizz). Estes recursos possibilitam a interação professor/aluno de forma síncrona ou assíncrona e podem tornar o processo de aprendizagem tão eficaz quanto o ensino presencial, mas a sua integração estratégica no processo formativo demanda formação e competência digital dos professores (Santos Junior e Monteiro, 2020).

O estudo de Cani et al. (2020) apresenta diversos aplicativos e recursos educacionais (gratuitos) que podem ser utilizados para o trabalho online nas escolas e evidencia algumas possibilidades de estratégias pedagógicas com utilização das TIC. Também Silveira et al. (2020) apresenta algumas alternativas tecnológicas que podem ser adotadas para apoiar o ensino remoto: a Sala de Aula invertida, a aprendizagem baseada em problemas (PBL - Problem Based Learning) ou a aprendizagem baseada em projeto, e o software Ardora para a criação de atividades lúdicas. Se junta a estes, o estudo de Nascimento, Benedetti e Santos (2020) que demonstra o potencial do jogo Plague Inc. para apoio ao ensino de Ciências, que propicia o engajamento do aluno e possibilita atividades interdisciplinares com conteúdos de outras disciplinas.

\subsection{Metodologias e práticas pedagógicas adotadas}

Nesta categoria, buscamos responder a outras duas questões: Quais metodologias e atividades foram utilizadas pelos professores? As estratégias adotadas garantem a participação e aprendizagem de todos os alunos nas circunstâncias que vivemos?

Como já dito anteriormente, tanto no Brasil quanto em Portugal, o fechamento das escolas e a suspensão das atividades letivas presenciais levaram as escolas públicas e privadas a adotarem abruptamente um modelo de ensino não presencial com recurso a tecnologias digitais. Os professores tiveram que adaptar, de um momento para outro, suas práticas pedagógicas e planos de ensino a um modelo de ensino à distância, em muitos casos, sem os conhecimentos e competências digitais essenciais para promover uma aprendizagem de qualidade. Concordamos com Moreira, Henriques e Barros (2020), que as instituições educacionais e os professores foram forçados a adotar práticas de ensino remoto de emergência que muito diferenciam das práticas de uma educação online de qualidade. Em caráter de urgência, a reestruturação curricular para uma modalidade EaD seria inviável (Almeida e Alves, 2020).

Neste sentido, os estudos revelam que os professores foram forçados a aprender subitamente a utilizar plataformas virtuais de aprendizagem, sistemas de videoconferência e outros recursos tecnológicos. Entretanto, na maioria dos casos, estas tecnologias foram e estão sendo utilizadas numa perspectiva instrumental, reduzindo as metodologias e as práticas pedagógicas a um ensino puramente transmissivo (Moreira, Henriques e Barros, 2020; Santana Filho, 2020), em que os professores prestam tutoria eletrônica, disponibilizam material online e interagem com seus alunos de forma síncrona ou assíncrona, com pouca interatividade e feedback insuficiente (Almeida e Alves, 2020; Vasconcelos Soares e Colares, 2020).

Evidencia-se a necessidade de formação docente que possibilite o desenvolvimento de competências digitais, de modo a serem capazes de modificar suas práticas pedagógicas com uso dos recursos tecnológicos (Silva Monteiro, 2020). Para além do domínio tecnológico, tornase imprescindível o desenvolvimento de habilidades autorais e competências digitais docentes para sintetizar, produzir, "remixar" e compartilhar conhecimentos no ciberespaço, de modo que os professores sejam capazes de criar um ambiente inovador, com uma dinâmica que se diferencie das práticas transmissivas historicamente consolidadas na educação (Almeida e Alves, 2020). O modelo de formação inicial de professores precisa ser (re)pensado/adaptado para as demandas da contemporaneidade (Barreto e Rocha, 2020). Segundo estes autores, no atual contexto da educação remota, a reprodução de uma metodologia de ensino tradicional tem interferido negativamente no engajamento e motivação dos estudantes nas atividades à distância. 
Moreira, Henriques e Barros (2020) salientam a importância e urgência de transitar deste ensino remoto de emergência, importante numa primeira fase, para uma educação digital em rede de qualidade, e apresentam, resumidamente, os princípios básicos para o design de um ambiente online, relacionado à organização, seleção de recursos, preparação e avaliação de eatividades de aprendizagem.

O estudo de Gonçalves (2020) sugere que, entre outras, o professor pode utilizar duas abordagens metodológicas para as sessões de formação online: ensino síncrono por videoconferência (aulas expositivas) e aula online invertida (flipped classroom), sendo a videoconferência usada essencialmente para esclarecimento de dúvidas e trabalho prático. Na sala de aula invertida, o aluno realiza atividades em casa, participando posteriormente em atividades síncronas. Geralmente, essas atividades correspondem a aulas de apoio à aprendizagem, baseadas em atividades práticas, com conteúdos previamente disponibilizados. Ressalta ainda que o uso dessas tecnologias deve ser devidamente integrado com as metodologias pedagógicas, as tipologias de conteúdos e as estratégias de motivação mais adequadas.

Neste sentido, Nascimento e Rosa (2020) descrevem um relato de experiência relacionado à implantação do método sala de aula invertida, que revelou ser uma ferramenta viável para potencializar e dar continuidade na rotina de estudos, com efetiva participação dos estudantes em todas as ações propostas e aprendizagem do conteúdo proposto, colocando o aluno no centro da construção do conhecimento e o professor como mediador e orientador da aprendizagem.

Silva Monteiro (2020) defende que cada rede de ensino encontre mecanismos próprios, de acordo com a sua realidade e aponta para a possibilidade de materialização do que denomina "currículo de transição". Sejam quais forem as estratégias e metodologias adotadas, devem garantir a participação e a aprendizagem de todos os alunos. Para Ferreira e Gonçalves (2020), medidas educativas de igualdade, equidade e inclusão devem ter em conta a diversidade de alunos do país, em particular no que diz respeito ao acesso a ferramentas, como a internet e banda larga; as condições das suas moradias, se permitirem ou não espaços reservados para que estes acompanhem o ensino remoto; bem como alunos que necessitam de acompanhamento adicional. Segundo a autora, em Portugal, recorreu-se também a televisão por cabo e por satélite - RTP Memória, com emissão de conteúdos pedagógicos temáticos, lecionados por professores/as, para alunos do ensino básico.

Para Carvalho (2020), os três eixos norteadores de uma educação de qualidade - o acesso, a participação e a aprendizagem efetiva de todos os alunos precisam ser reequacionados. As mudanças devem ser acompanhadas de garantias de acesso às múltiplas e diversas oportunidades de aprendizagem organizadas pelas escolas. Questionando-se sobre como garantir que todos os alunos participam e aprendem nas circunstâncias excepcionais que agora vivenciamos, o autor aponta para as fragilidades, sobretudo daqueles com maiores fragilidades socioeconômicas, no que respeita às suas competências digitais e à sua "capacidade" para aprender neste modelo online.

Camacho et al. (2020) destaca a importância da visibilidade das necessidades do aluno em termos de preparação para estudar por meio das tecnologias digitais e, principalmente, as situações de vulnerabilidade social que não dispõem de todos os recursos para acesso aos ambientes virtuais de aprendizagem e conteúdos disponibilizados online. É necessário compreender a diversidade, a acessibilidade e os princípios de inclusão para que se atente de forma isonômica as demandas discentes em situação de vulnerabilidade social.

Conforme Couto, Couto e Cruz (2020), as experiências ciberculturais, incluindo a educação online, alcançam uma parcela restrita da população e os desafios para educar com tecnologias digitais ainda são imensos e precisam ser democratizados. As desigualdades no acesso e usos 
da Internet em muitas áreas urbanas periféricas e zonas rurais reforçam as diferenças marcadas por vulnerabilidades sociais. Com tantas limitações para acessar e usar a Internet, estudantes das classes socioeconômicas mais desfavorecidas não conseguem estudar.

\subsection{Análises prospectivas e oportunidades pós-pandemia}

Nesta categoria, procuramos respostas para a última questão da investigação: Quais as tendências e os dilemas da Educação Básica e Secundária após a pandemia do COVID-19? Pensamos que ainda é cedo para uma análise mais aprofundada e acertada desta questão. Alguns dos estudos revisados apresentam uma visão mais otimista (Azevedo, 2020; Cani et al., 2020; Fonseca e Franco, 2020; Martins, 2020; Sousa, Borges e Colpas, 2020); e outros focam mais em aspectos negativos como a falta de consideração dos aspectos qualitativos no processo ensino aprendizagem (Oliveira, Gomes e Barcellos, 2020; Santos et al, 2020), a desigualdade social no sistema educacional brasileiro e a necessidade de se garantir equidade nas políticas de substituição da educação presencial pela educação mediada por tecnologias digitais (Arruda, 2020; Avelino e Mendes, 2020; Camacho et al, 2020).

Considerando a dimensão da equidade no acesso às tecnologias digitais, de maneira a permitir que todos os alunos possam desenvolver atividades pedagógicas de forma remota, Arruda (2020) ressalta que a situação emergencial é também momento propício para fomentar uma política nacional de universalização do acesso às informações e conhecimentos disponibilizados pela internet, de modo a favorecer a diminuição das desigualdades existentes entre alunos das escolas públicas e privadas.

O estudo realizado por Oliveira, Gomes e Barcellos (2020) indica que as medidas consideradas mais óbvias para o período pós-pandemia, como o ensino remoto, o uso de tecnologias e o aumento da carga horária, dificilmente constituem soluções robustas para o enfrentamento das consequências da interrupção do calendário escolar, e que, embora estejam sendo incorporadas ao dia a dia da escola com maior intensidade, essas três opções dificilmente contêm os elementos para ajudar na recuperação dos alunos mais prejudicados. Para estes autores, as alternativas mais efetivas incluem, inicialmente, um diagnóstico dos alunos como base para a retomada dos programas de ensino. E, a partir daí, intervenções que incluem, do lado pedagógico, o ensino estruturado, o uso de métodos adequados de alfabetização, o uso estratégico dos deveres de casa e de programas de leitura; e para os alunos com mais dificuldade, programas intensivos de tutoria em pequenos grupos.

Fonseca e Franco (2020) apresentam uma proposta para abordagem da pandemia da COVID-19 no Ensino de Ciências, partindo de pressupostos da Ciência-Tecnologia-Sociedade (CTS), de modo a possibilitar discussões a nível social, político e ambiental, além de questões sobre a divisão de classes econômicas, credibilidade e descrença na ciência, tomada de decisões democráticas e participação social. Segundo estes autores, a abordagem das dimensões políticas, econômicas e ambientais no desenvolvimento destes assuntos poderá contribuir para um ensino coerente com uma concepção crítica de educação. Sugerem abordagens de informações da mídia sobre a pandemia com destaque para as notícias falsas; para questões da saúde e possíveis relações com conteúdos conceituais; abordagens referentes à Ciência e Tecnologia e suas implicações para a Sociedade; e a abordagem de questões relativas à crise socioambiental desvelada e que agrava as desigualdades. Para os autores, a proposta apresentada é uma possibilidade de desencadear práticas educativas comprometidas com um ensino contextualizado, interdisciplinar e que abordagens temáticas favorecem a discussão de questões emergentes da sociedade, preocupadas com um ensino efetivamente crítico.

Sousa, Borges e Colpas (2020) defendem a metodologia dos Episódios de Aprendizagem Situados como possível contribuição relevante aos esforços de desenvolvimento de uma "revolução digital inclusiva" pós-pandemia nas escolas, e potencialmente capaz de propiciar 
processos educativos relacionais entre ambientes formais e informais, com foco na interação, no diálogo e na pesquisa, por meio da utilização crítica das TIC no ensino e aprendizagem.

Martins (2020) preconiza que a sociedade se adaptará, rapidamente, aos avanços oferecidos pelas TIC, principalmente no que se refere à forma de ensinar e aprender e que, no paradigma educacional pós-pandemia, prevalecerá a educação semipresencial mediada por recursos educacionais digitais. Contudo, as preocupações e cuidados devem se voltar ao que realmente importa: as condições de trabalho docente, a qualidade do processo de ensino-aprendizagem, a relevância dos temas a serem abordados, o desenvolvimento de práticas pedagógicas centradas no aluno, o resgate das responsabilidades discentes sobre o seu processo de aprendizagem e o envolvimento das famílias no processo de formação das crianças e jovens.

Segundo Azevedo (2020), as escolas portuguesas apresentam patamares distintos no que diz respeito ao visionamento e aproveitamento das oportunidades que eventualmente irão se abrir com esta disrupção, e que estas oportunidades dependem da capacidade que cada escola tem para as identificar, analisar e aproveitar do melhor modo. Para este autor, se as escolas básicas e secundárias portuguesas trabalhassem mais em rede, em dinâmicas de cooperação, seria mais fácil usufruir das oportunidades vindouras, relativamente às instabilidades e desequilíbrios no sistema escolar tradicional que poderão propiciar processos de inovação e mudança, tais como: a possibilidade de explorar e conciliar tempos e espaços de ensino e aprendizagem; a percepção da relevância do trabalho autônomo dos alunos e das possibilidades concretas de o promover; o foco mais intenso em torno dos processos de aprendizagem e menos sobre a avaliação das aprendizagens; a grande quantidade de materiais didáticos digitais que fomentam metodologias ativas e que se deveriam recolher, analisar e organizar; paradoxalmente, a proximidade, a relação educativa e a personalização dos percursos de aprendizagem e de desenvolvimento podem ampliar-se num tempo de distanciamento social e abrir novos horizontes a alunos e a educadores.

Concordamos com Cani et al. (2020), que a pandemia da COVID-19 despertou na humanidade um sentimento, a importância e urgência de todos desenvolverem habilidades e competências digitais. Esta situação inesperada criou oportunidades para aqueles que estavam habituados a pensar e lidar com as tecnologias como uma opção, a se apropriarem dos recursos tecnológicos de alguma forma. Neste sentido, Neto (2020) questiona sobre qual seria a função do professor na contemporaneidade, agora e após o período de pandemia, e aponta para a necessidade de reflexão na prática pedagógica de como a formação dos docentes para a integração das tecnologias nas salas de aula podem resultar em projetos e pesquisa com abordagem interdisciplinar, de modo que as novas relações estabelecidas pela tecnologia propiciem o repensar pragmático do processo de ensino-aprendizagem e da construção de novas metodologias pedagógicas.

\section{Considerações finais}

A pandemia por COVID-19 obrigou as instituições educacionais e os professores, em nível mundial, a alterar drasticamente as suas práticas educativas. As circunstâncias nem um pouco ideais que cercaram a transição para o ensino remoto tem permitido a professores e estudantes experimentar contextos comunicativos emergentes. Da sala de aula presencial, estudantes no mundo inteiro, passaram a ter aulas numa sala de aula virtual, de um momento para o outro, sem um preparo prévio, e muitos deixaram de ter qualquer aula.

A adaptação a esta nova realidade não foi um processo fácil nem o mais adequado, pelo menos em alguns níveis de ensino, mas foi o possível face aos acontecimentos. A urgência na continuidade das atividades letivas de manter a intervenção pedagógica orientada por conteúdos e instrumentos de memorização e controle ainda prevalecem, tanto nas ações dos gestores da 
educação pública quanto nas instituições educacionais privadas. Com base nos resultados desta RSL, podemos afirmar que a tendência que deriva do ensino remoto é ainda mais desigualdade, mais fragilidade na profissão docente, mais desestruturação da educação pública, haja vista as limitações docentes quanto à sua competência digital e habilidade para a transposição didática (Dias; Moreira; Mendes, 2016) do presencial para o online e as limitações de infraestrutura tecnológica e de conectividade, associadas principalmente, aos estudantes das escolas públicas em situação de vulnerabilidade.

Ainda é cedo para avaliar a totalidade dos impactos, retrocessos e progressos na educação em função das medidas adotadas neste período da pandemia, mas certamente, tem sido de muito aprendizado para a comunidade escolar, no sentido de novas perspectivas educacionais em todos os níveis de ensino. É preciso repensar a concepção de aprendizagem, da ação pedagógica, do currículo e dos próprios sujeitos do processo educacional; é preciso fomentar a tendência do ensino online aliado ao ensino presencial na educação básica e secundária, em prol de uma educação transformadora, emancipatória, inclusiva e de qualidade.

Por fim, entendemos que a interação e a qualidade da formação mediadas pelas TIC na EaD estão diretamente vinculadas à competência digital dos envolvidos no processo de ensinoaprendizagem (Oliveira; Coelho; Vieira, 2017), especialmente do professor, sendo condição sine-qua-non para promover uma educação online de qualidade. Essa competência traduz-se, para além da competência técnica em relação ao uso de plataformas e dos recursos digitais, na capacidade de organizar e orientar didaticamente o processo de ensino-aprendizagem à distância, na presença virtual constante e na habilidade para ler e escrever com fluência em ambientes digitais.

\section{Referências}

Almeida, B. O. \& Alves, L. R. G. (2020). Letramento digital em tempos de COVID-19: uma análise da educação no contexto atual. Debates em Educação, 12(28). [GS Search]

Arruda, E. P. (2020). Educação remota emergencial: elementos para políticas públicas na educação brasileira em tempos de Covid-19. EmRede - Revista de Educação a Distância, 7(1), 257-275. [GS Search]

Avelino, W. F. \& Mendes, J. G. (2020). A realidade da educação brasileira a partir da COVID19. Boletim de Conjuntura (BOCA), 2(5), 56-62. doi: 10.5281/zenodo.3759679 [GS Search]

Azevedo, J. (2020). COVID e educação: da emergência às oportunidades. Ensinar e aprender em tempo de COVID 19: entre o caos e a redenção, 83-86. [GS Search]

Barreto, A. C. F. \& Rocha, D. S. (2020). COVID 19 e Educação: resistências, desafios e (im) possibilidades. Revista Encantar-Educação, Cultura e Sociedade, 2, 01-11. doi: 10.46375/encantar.v2.0010 [GS Search]

Cabral, I. (2020). O ensino e a aprendizagem em tempos de COVID-19 à luz da teoria da ação comunicativa de Habermas. Ensinar e aprender em tempo de COVID 19: entre o caos e a redenção, 67-75. [GS Search]

Camacho, A. C. L. F., Fuly, P. D. S. C., dos Santos, M. L. S. C., \& de Menezes, H. F. (2020). Alunos em vulnerabilidade social em disciplinas de educação à distância em tempos de COVID-19. Research, Society and Development,9(7), e275973979-e275973979. doi: $\underline{10.33448 / \mathrm{rsd}-\mathrm{v} 9 \mathrm{i} 7.3979}$ [GS Search] 
Cani, J. B., Sandrini, E. G. C., Soares, G. M., \& Scalzer, K. (2020). Educação e COVID-19: a arte de reinventar a escola mediando a aprendizagem "prioritariamente" pelas TDIC. Revista Ifes Ciência, 6(1), 23-39. doi: 10.36524/ric.v6i1.713 [GS Search]

Carvalho, M. (2020). Acesso, equidade e aprendizagem: desafios em tempos de Covid 19. Ensinar e aprender em tempo de COVID 19: entre o caos e a redenção, 119-122. [GS Search]

Castells, M. (1999). A sociedade em rede. São Paulo: Paz e Terra.

CGI.BR (2019). Pesquisa Sobre o Uso das Tecnologias de Informação e Comunicação nos domicílios brasileiros: TIC DOMICÍLIOS 2018. São Paulo: Comitê Gestor da Internet no Brasil. Disponível em: http://twixar.me/DhlT. Acesso em: 26 Jun. 2020.

Coutinho, A. S., \& Côco, V. (2020). Educação Infantil, políticas governamentais e mobilizações em tempos de pandemia. Práxis Educativa, 15, 1-15. doi: 10.5212/PraxEduc.v.15.16266.088 [GS Search]

Couto, E. S., Couto, E. S., \& Cruz, I. D. M. P. (2020). \#fiqueemcasa: educação na pandemia da COVID-19. Interfaces Científicas-Educação, 8(3), 200-217. doi: 10.17564/23163828.2020v8n3p200-217 [GS Search]

Dias, P., Moreira, D., \& Mendes, A. Q. (2016). Práticas e cenários de inovação em educação online. Práticas e cenários de inovação em educação online. [GS Search]

Faria, Paulo M. (2015). Revisão Sistemática da Literatura: teoria e prática para o desenvolvimento profissional docente e inovação educativa com TIC. ed. 1, ISBN: 978-9898765-27-7. Santo Tirso: Whitebooks.

Ferreira, A. R., \& Gonçalves, D. (2020). Políticas educativas em tempos de COVID em Portugal: que relação com a igualdade, equidade e inclusão em educação? Revista Galega de Educación, 49-52. [GS Search]

Fonseca, E. M., \& Franco, R. M. (2020). Em tempos de Coronavírus: reflexões sobre a pandemia e possibilidades de abordagem no Ensino de Ciências a partir da Educação CTS. Research, Society and Development, 9(8). doi: 10.33448/rsd-v9i8.5946 [GS Search]

Gonçalves, V. (2020). COVIDados a inovar e a reinventar o processo de ensino-aprendizagem com TIC. Revista Pedagogia em Ação, 13(1), 43-53. [GS Search]

Hodges, Charles \& Moore, Stephanie \& Lockee, Barbara \& Trust, Torrey \& Bond, Mark. (2020). The Difference Between Emergency Remote Teaching and Online Learning. Educause Review. Disponível em: http://er.educause.edu/articles/2020/3/the-differencebetween-emergency-remote-teaching-and-online-learning [GS Search]

Jesus Pereira, A., Narduchi, F., \& de Miranda, M. G. (2020). Biopolítica e Educação: os impactos da pandemia do covid-19 nas escolas públicas. Revista Augustus, 25(51), 219-236. doi: 10.15202/1981896.2020v25n51p219 [GS Search]

Joye, C. R., Moreira, M. M., \& Rocha, S. S. D. (2020). Educação a Distância ou Atividade Educacional Remota Emergencial: em busca do elo perdido da educação escolar em tempos de COVID-19. Research, Society and Development, 9(7), e521974299-e521974299. doi: $\underline{10.33448 / \mathrm{rsd}-\mathrm{v} 9 \mathrm{i} 7.4299}$ [GS Search]

Kitchenham, B., \& Charters, S. (2007). Guidelines for performing systematic literature reviews in software engineering. Technical Report EBSE- 01, Keele University.

Levy, P. (1999). Cibercultura. São Paulo: Ed. 34. 
Martins, R. X. (2020). A covid-19 e o fim da educação a distância: um ensaio. EmRede-Revista de Educação a Distância, 7(1), 242-256. [GS Search]

Ministério da Educação (2020). Portaria $n^{\circ} 343$, de 17 de Março de 2020 que Dispõe sobre a substituição das aulas presenciais por aulas em meios digitais enquanto durar a situação de pandemia do Novo Coronavírus - COVID-19. MEC. Disponível em: https://www.mec.gov.br/. Acesso em: 22 Abr. 2020.

Moreira, J. A., Henriques, S., \& Barros, D. M. V. (2020). Transitando de um ensino remoto emergencial para uma educação digital em rede, em tempos de pandemia. Dialogia, 351364. [GS Search]

Moreira, M. E. S., da Silva Cruz, I. L., Sales, M. E. N., Moreira, N. I. T., de Castro Freire, H., Martins, G. A., \& Popolim, R. S. (2020). Metodologias e tecnologias para educação em tempos de pandemia COVID-19/Methodologies and technologies for education in times of pandemic COVID-19. Brazilian Journal of Health Review,3(3), 6281-6290. doi: 10.34119/bjhrv3n3-180 [GS Search]

Nascimento, F. G. M., Benedetti, T. R., \& dos Santos, A. R. (2020). Uso do Jogo Plague Inc.: uma possibilidade para o Ensino de Ciências em tempos da COVID-19/Use of the Pest Game Inc.: a possibility for Science Education in the days of COVID-19. Brazilian Journal of Development, 6(5), 25909-25928. doi: 10.34117/bjdv6n5-156 [GS Search]

Nascimento Borba, R. C., Teixeira, P. P., Fernandes, K. D. O. B., Bertagna, M., Valença, C. R., \& de Souza, L. H. P. (2020). Percepções docentes e práticas de ensino de ciências e biologia na pandemia: uma investigação da Regional 2 da SBEnBio. Revista de Ensino de Biologia da SBEnBio, 153-171. doi: 10.46667/renbio.v13i1.337 [GS Search]

Nascimento, F. G. M., \& da Rosa, J. V. A. (2020). Princípio da sala de aula invertida: uma ferramenta para o ensino de química em tempos de pandemia. Brazilian Journal of Development, 6(6), 38513-38525. doi: 10.34117/bjdv6n6-409 [GS Search]

OECD (2020a). Supporting the continuation of teaching and learning during the COVID-19 Pandemic Annotated resources for online learning. Paris: OECD Publishing. Disponível em: https://www.oecd.org/education/Supporting-the-continuation-of-teaching-and-learningduring-the-COVID-19-pandemic.pdf. Acesso em: 12 Mai. 2020.

OECD (2020b). A framework to guide education response to the COVID - 19 Pandemic. Paris: OECD Publishing.

Oliveira, B. R.; Coelho, J. I. F.; Vieira, M. F. (2017). Limites e possibilidades do uso das TDICs no processo de formação de professores na modalidade a distância: a experiência do Programa Escola de Gestores na Universidade Federal de Ouro Preto. Dialogia, São Paulo, n. 27, p. 65-78, set./dez. [GS Search]

Oliveira, J. B. A., Gomes, M., \& Barcellos, T. (2020). A Covid-19 e a volta às aulas: ouvindo as evidências. Ensaio: Avaliação e Políticas Públicas em Educação, 28(108), 555-578. doi: 10.1590/s0104-40362020002802885 [GS Search]

OPAS/OMS. Organização Pan-Americana da Saúde/Organização Mundial da Saúde. Disponível em

https://www.paho.org/bra/index.php?option=com_content\&view=article\&id=6101:covid19 \&Itemid=875. Acesso em 15 de Junho de 2020.

Petticrew, M., \& Roberts, H. (2008). Systematic reviews in the social sciences: A practical guide. John Wiley\& Sons. 
Santana Filho, M. M. (2020). Educação geográfica, docência e o contexto da pandemia COVID19. Revista Tamoios, 16(1). doi: 10.12957/tamoios.2020.50449 [GS Search]

Santos, E. T., Chavez, E. S., Silva, A. A. M., Lordano, G. A., Ayach, L. R., da Anunciação, V. S., \& Batista, R. L. (2020). COVID 19 e os impactos na educação: percepções sobre Brasil e Cuba. Hygeia-Revista Brasileira de Geografia Médica e da Saúde, 450-460. doi: 10.14393/Hygeia0054555 [GS Search]

Santos Junior, V. B., \& Monteiro, J. C. S. (2020). Educação e COVID-19: as tecnologias digitais mediando a aprendizagem em tempos de pandemia. Revista Encantar-Educação, Cultura e Sociedade, 2, 01-15. [GS Search]

Silva Monteiro, S. (2020). (Re)inventar educação escolar no Brasil em tempos da COVID19. Revista Augustus, 25(51), 237-254. doi: 10.15202/1981896.2020v25n51p237 [GS Search]

Silveira, S. R., Bertolini, C., Parreira, F. J., da Cunha, G. B., \& Bigolin, N. M. (2020). O Papel dos licenciados em computação no apoio ao ensino remoto em tempos de isolamento social devido à pandemia da COVID-19. Série Educar-Volume 40 Prática Docente, 35. [GS Search]

Sousa, G. R., Borges, E. M., \& Colpas, R. D. (2020). Em defesa das tecnologias de informação e comunicação na Educação Básica: diálogos em tempos de pandemia. PLURAIS - Revista Multidisciplinar, 5(1), 146-169. doi: 10.29378/plurais.2447-9373.2020.v5.n1.146-169

UNESCO (2020a). Disrupção educacional e resposta COVID-19. Disponível em https://en.unesco.org/covid19/educationresponse. Acesso em 03 Jun. 2020.

UNESCO (2020b). COVID-19 impact on education. Disponível em: https://en.unesco.org/covid19/educationresponse. Acesso em: 02 Jun. 2020.

Vasconcelos Soares, L., \& Colares, M. L. I. S. (2020). Educação e tecnologias em tempos de pandemia no Brasil. Debates em Educação, 12(28). doi: $\underline{10.28998 / 2175-}$ 6600.2020v12n28p19-41 [GS Search]

Vieira, M. F. (2018). A Gestão de EaD no contexto dos Polos de Apoio Presencial: Proximidades e diferenças entre a Universidade Aberta do Brasil e as Instituições universitárias privadas. Tese (Doutoramento em Educação) - Universidade Aberta. Disponível em: http://hdl.handle.net/10400.2/7182. Acesso em: 28 Jul. 2018. 